\title{
Leptospirosis y Embarazo
}

\author{
Alfredo Barraza T.*; Guillermo Acosta Osio**; Gina Saad***
}

\section{RESUMEN}

La leptospirosis, producida por varios serotipos de la Leptospira, es una enfermedad infecciosa aguda, que afecta a todo el mundo, se encuentran favorecidas las zonas húmedas y el pH del suelo cercano a la neutralidad, se multiplica en la sangre y puede invadir cualquier tejido del organismo. El diagnóstico etiológico se establece por demostración de las leptospiras en sangre, orina oLCR, además por reacciones serológicas; en términos generales la enfermedad tiene buen pronóstico, pero existen cepas virulentas que provocan mortalidad que va de un 15 a un $40 \%$.

Presentamos un caso de leptospirosis durante el embarazo, manejada por el Departamento de Ginecología y Obstetricia del Hospital Universitario Metropolitano; paciente de 29 años G2 P1 con Rho (-) no isoinmunizada, con un embarazo de 36 semanas, recibiendo como tratamiento, una vez realizado el diagnóstico, penicilina G, evolucionando satisfactoriamente, ella y su bebé.

PALABRAS CLAVES: Leptospirosis, embarazo, complicaciones, diagnóstico, tratamiento.

\section{ABSTRACT}

The leptospirosis, produced for various serotipos of Leptospira, is an acute infection diseases, everybody can be affected, it is most common in the web areas, with a neutral pH of the earth. It develops in the blood and can produce invasion in all organism tissues. The etiological diagnostic could be establish by leptospiras demonstration in blood, urine or CRL, or for serologic reactions; in general the diseases has good prognostic, but some kinds of leptospiras could be produce between the 15 and $40 \%$ of mortality.

We presented one case of leptospirosis of a pregnant women, 29 years, G2 P1, Rho (-) without isoinmunitation, she had 36 weeks of gestacional ages when the infection was found. Once the diagnosis was made, we treatedher whit $G$ penicillin, obtaining a satisfactory evolution in the mother and her baby.

KEY WORDS: Leptospirosis, pregnancy, complications, diagnostic, treatment.

\section{Introducción}

La leptospirosis es una enfermedad infecciosa aguda, febril, producida por varios serotipos de la Leptospira interrogans, en este momento se identifican 180 serotipos que pertenecen a 16 serogrupos, las principales son: $\mathrm{L}$. Icterohaemorrhagiae, L. Canicola, L. Pamona, L. Ballum, L. Bataviae, L. Grippotyphosa, L. Pyrogenes, L. Autumnalis, L. Austrialis, L. Hyos, L. Menigeorgia, L. Hebdomadis. $(1,2)$

\footnotetext{
* Gineco/Obstetra Coordinador de Pos Grado, Universidad y Hospital Universitario Metropolitano

Gineco/Obstetra, Profesor Titular, Director Departamento, Universidad y Hospital Universitario Metropolitano

Residente primer año, Universidad y Hospital Universitario Metropolitano. Dirección: K 42 \# 75b-82,

www.unimetro.edu.co, E-mail: gacostao@yahoo.com
}

La leptospirosis es una zoonosis que afecta a todo el mundo, se encuentran favorecidas las zonas húmedas y el $\mathrm{pH}$ del suelo cercano a la neutralidad. El contagio puede ser indirecto o directo, el primero se hace a través de sangre o la orina que puede contaminar el suelo, las aguas, o los alimentos y la leptospira puede penetrar a través de las mucosas conjuntival, oral o nasal o a través de pequeñas lesiones en la piel. El contagio directo se da por contacto con el animal, con su carne o sus productos después del sacrificio. También se ha demostrado que se transmite a través del coito. (1)

La leptospira se multiplica en la sangre y puede invadir cualquier tejido del organismo, en las necropsias se han encontrado hemorragias petequiales o equimóticas en músculos, riñones, hígado, suprarrenales, estómago, bazo y pulmones.(3) Las leptospiras se localizan y multiplican principalmente en el epitelio de los túbulos distales del riñón. También se encuentra invasión e infiltración leucocitaria en el hígado donde producen degeneración turbia, en las meninges producen engrosamiento, en el corazón cambios propios de miocarditis, hemorragias y neumonitis a escala pulmonar. $(2,3)$ 
El período de incubación es de 2 a 21 días con un cuadro clínico que asemeja un proceso gripal, por lo general la enfermedad es monofásica y ocasionalmente bifásica, en el primer estadío la leptospira invade sangre y LCR, en la fase inicial el paciente refiere cefalea, fiebre y mialgias, hemorragias subconjuntivales y problemas gastrointestinales, esta fase dura aproximadamente de 4 a 7 días, pero persiste la leptospira en el parénquima renal, a veces los pacientes refieren faringitis y linfadenopatías; hasta este punto se resuelven generalmente los síntomas, sin secuelas. Un pequeño porcentaje de pacientes progresa a una segunda fase de la enfermedad, conocida como fase inmune, se relaciona con la aparición de anticuerpos en el organismo y la resolución de la leptospiremia. La meningitis aséptica y la uveitis, ocurren durante esta fase. Es menos común la encefalitis, mielitis y neuropatías. Muchos pacientes no presentan ictericia. La forma mas grave de la enfermedad es conocida como enfermedad de Weil caracterizada por oliguria, colapso circulatorio, tendencia a la hemorragia e ictericia y la mortalidad ocurre por lo general por falla hepática, renal o hemorragia pulmonar, además puede afectar muchos otros sistemas. $(1,2,3,4)$

El diagnóstico del laboratorio revela leucocitosis, ictericia, trombocitopenia y la sedimentación está elevada. El examen de orina muestra albuminuria, cilindros y eritrocitos en el sedimento, aumento del nitrógeno uréico y la urea, es común la elevación de la bilirrubina y las pruebas hepáticas. $(1,2,5)$

El diagnóstico etiológico se establece por demostración de las leptospiras en sangre, orina o LCR, además por reacciones serológicas; comúnmente las mas empleadas son la hemaglutinación, contrainmunoelectroforesis, inmunoflorescencia indirecta, macroaglutinación del antígeno termo resistente, análisis inmuno enzimáticos, que son técnicas genero específicas utilizadas para detectar anticuerpos de tipo IgM. Actualmente se están desarrollando técnicas de biología molecular (PCR, campo pulsado, hibridación) para la detección del genero leptospira así como para la tipificación de los serovares infectantes. Se debe hacer estudios de sueros pareados tomados durante la fase aguda y convaleciente para observar seroconversión o aumento de títulos de anticuerpos. $(2,5,6)$

\section{Caso Clínico}

A continuación presentamos un caso de leptospirosis durante el embarazo: Se trata de una paciente de 29 años G2 P1 con Rho (-) no isoinmunizada, la cual se realizó un control prenatal adecuado desde las 9 semanas de gestación hasta las 34 semanas, con sus respectivos paraclínicos y controles ecográficos de evolución normal; en su último control el 10 de marzo, se le ordenó ecografía que reporta placenta con abundantes calcificaciones que no correspondía a la edad gestacional, por lo que se ordena monitorización fetal anteparto (PNS) que se reporta como reactiva, se ordena nuevo control con PNS en 1 semana.

El día 20 de marzo de 1999, después de ingesta de una comida en establecimiento público, empezó a presentar vómitos de contenido alimentario, en número de 6 , asocia- dos a deposiciones líquidas, amarillas, fétidas en número de 4, mejorando el cuadro espontáneamente. El día 22 de marzo presenta mialgias y en piel rash no pruriginoso que se borra a la digitopresión.

El día 23 de marzo presenta a las 6:00 a.m., ruptura de membranas e inicia trabajo de parto, por lo que acude a la urgencia del Hospital Universitario Metropolitano (HUM) a las 7:00 a.m., encontrándose paciente en aparente buen estado general T.A. $120-50 \mathrm{mmhg}, \mathrm{FC} / 90$ por minuto, FR/ 16 por minuto. A nivel cardiopulmonar se encontraba normal, el abdomen con AU de $33 \mathrm{~cm}$, feto longitudinal, dorso izquierdo, cefálico, encajado, $\mathrm{FCF} / 140$ por minuto, dinámica uterina de 4 contracciones en 10 minutos de buena intensidad y 40 segundos de duración. Genitales con dilatación de $10 \mathrm{~cm}$, borramiento del $100 \%$, estación +1 , membranas rotas, variedad de posición de la presentación ODA. Se ordena canalizar y trasladar inmediatamente a sala de parto donde a las 7:15 a.m. se realiza episiotomía mediana, se atiende parto vaginal normal sin complicaciones y se traslada la paciente a su habitación. Dos horas mas tarde, presenta vómito amarillento, se encuentra tensión arterial de 280/130 mmhg, distensión abdominal y ligero tinte ictérico en escleras, se hace impresión clínica de Síndrome de Hellp, se ordena paraclínicos, sulfato de magnesio y nifedipina, se estabilizan cifras tensionales, pero se acentúa cuadro de edema, distensión abdominal e ictericia, asociado a oliguria.

Se reciben reportes de paraclínicos, encontrándose creatinina de 2.0, ácido úrico de 9.1, TP y TPT de 33 y 56 seg. respectivamente, $\mathrm{LDH}$ de 1218 , bilirrubina de $10, \mathrm{Hb}$ de 10, granulaciones tóxicas, se piensa en CID y sepsis de foco a determinar, por lo que se solicita valoración a medicina interna, quienes consideran cuadro séptico con foco en estudio y se ordena hemocultivo, maxipime, metronidazol, dopamina, ranitidina, vitamina $\mathrm{K}$, valoración por hematología y nefrología.

El hematólogo ordena transfundir, pero empeora el estado general de la paciente y su función renal, la distensión abdominal es mas marcada, por lo que se ordena HIV, anticuerpos antileptospirosis y ecografía abdominal, la que reporta abundante líquido libre en cavidad abdominal, por lo anterior, es valorada por cirugía quien considera realizar paracentesis, extrayéndose $1000 \mathrm{cc}$ de líquido amarillento, el cual se envía a estudio y no reporta alteración, se pide valoración a gastroenterología y se considera su traslado a UCI, luego la paciente presenta episodio de hematemesis, microhemorragias en el ámbito de conjuntivas, dehiscencia de episiorrafía.

Se recibe reporte de HIV negativo y Leptospira positivo para cepa Icterohaemorrhagiae, se ordena tratamiento con penicilina y empieza a mejorar cuadro de la paciente, evolucionando satisfactoriamente dándosele de alta a los 10 días.

En cuanto al producto de la concepción, se obtuvo recién nacido pretérmino, con un peso de 2900 gramos, talla de $50 \mathrm{~cm}$, edad gestacional por Capurro de $36 \mathrm{sema-}$ nas, con apgar $4 / 10$ al minuto y $8 / 10$ a los 5 minutos, que mejoro espontánea y totalmente, también tenía riesgo de isoinmunización a Rho e incompatibilidad $\mathrm{ABO}$, que se descarto clínica y paraclínicamente, el grupo sanguíneo del recién nacido fue A y el Rho (+). Durante su estancia 
hospitalaria tuvo trastorno leve metabólico, caracterizado por hipoglicemia e hipocalcemia que se resolvió sin complicaciones, se le pidieron anticuerpos antileptospira que fueron negativos. Se dio de alta a los 5 días, y cabe anotar que las pruebas serológicas de la familia fueron negativas.

\section{Comentarios}

La infección por leptospirosis en el embarazo es similar a la que ocurre en mujeres no embarazadas, sin embargo se asocia durante el embarazo a un incremento en las perdidas fetales, esto es probablemente por la severidad de la enfermedad materna y no directamente por el feto, aunque la leptospira cruza la placenta. $(1,2,6)$ De acuerdo a Gleichel (1), Shaked reporto un caso de embarazo con leptospirosis y 34 semanas de gestación, quien tuvo un bebé saludable, como en nuestro caso, que si bien tuvo su hipoxia a los cinco minutos estaba recuperado posteriormente.

También se han reportado 5 pacientes infectadas antes de las 28 semanas, quienes tuvieron pérdidas fetales espontáneas, después de las 28 semanas se aumentó el riesgo de infección fetal, 4 de 9 embarazos, y 3 de 9 pacientes tuvieron pérdidas espontáneas. La leptospira fue aislada del hígado, pulmones, miocardio y placenta. (1) Carles reporta 11 casos de leptospirosis y embarazo en las Guayanas Francesas, con las muertes fetales en mas del $50 \%$ de los casos, manifestadas como abortos espontáneos o muerte in útero, ellos encontraron leptospira en el intestino fetal, corioamnionitis y vellositis crónica en las placentas. (1)
En el tratamiento se han usado múltiples antibióticos entre los cuales están las tetraciclinas, doxiciclina y la penicilina $G(1,2,6)$ que fue la utilizada por nosotros. Otros antibióticos han sido usados in vitro y han demostrado buena actividad entre los que se encuentran las cefalosporinas, eritromicina, gentamicina y las quinolonas. El maxipime y el metronidazol no tuvieron ningún efecto sobre la Leptospira en nuestra paciente. Definitivamente la droga de elección es la penicilina $\mathrm{G}$, sobre todo en el embarazo $\mathrm{y}$ ha demostrado su efectividad aun en las formas severas de la enfermedad $(1,4,6)$, gracias a esto fue como obtuvimos la evolución satisfactoria de nuestra paciente; siendo cierto que mejores resultados se obtienen mientras más precozmente se inicie el tratamiento $(1,4)$. Las dosis recomendadas de penicilina $G$ son 6 millones de unidades intravenosas para las 24 horas, durante 7 días, en términos generales la enfermedad tiene buen pronóstico, pero existen cepas virulentas que provocan mortalidad que va de un 15 a un $40 \%$, los índices de mal pronóstico son la ictericia y las manifestaciones de daño renal. $(2,5,6)$

Lo ideal sería el diagnóstico preciso y a tiempo para evitar las complicaciones y lo más importante es la prevención, siendo esta sencilla si seguimos las medidas higiénicas ya conocidas y que debemos transmitir o recordar a nuestros pacientes como son el lavado de manos, tener siempre las comidas tapadas, lavar y cocinar adecuadamente los alimentos, fumigaciones periódicas, no acumular basuras ni comidas descompuestas, ni objetos que sirvan para criar ratas. (7)

\section{BIBLIOGRAFIA}

1. Gleichel N, Buttino. L, Elkayam U, et al. Principles and practice of medical therapy in pregnancy, Ed Appleton and Lange, Ed 3, 1998.

2. Vélez H, Rojas W. Y colaboradores. Fundamentos de medicina. Enfermedades infecciosas. Ed CIB, Ed 5, 1994.

3. Hemeroteca. Icfes. Gov. Co. revistas. Comédica. Hallazgos histopatológicos en necropsias de leptospirosis. Jesús A. Pérez García. ML. Departamento de patología. Facultad de ciencias de la salud. Febrero 4 de 1999.
4. www.todocarabobo.com. Jornadas LRAE. Garcia-arelis.htm. Leptospirosis humana en pacientes febriles en un hospital de la ciudad de Maracaibo. Septiembre 18 de 1998.

5. www.argenet.com.ar. Leptospira, anticuerpos, método enzimoinmunoanálisis. Inhibición de la hemaglutinación, muestra, suero. Septiembre 15 de 1998.

6. www.geocites.com. Enfermedades bacterianas. Junio de 1998.

7. Acosta Osio, G. La Leptospirosis en Barranquilla, ¿una epidemia?, El Heraldo, Agosto, 1999. 